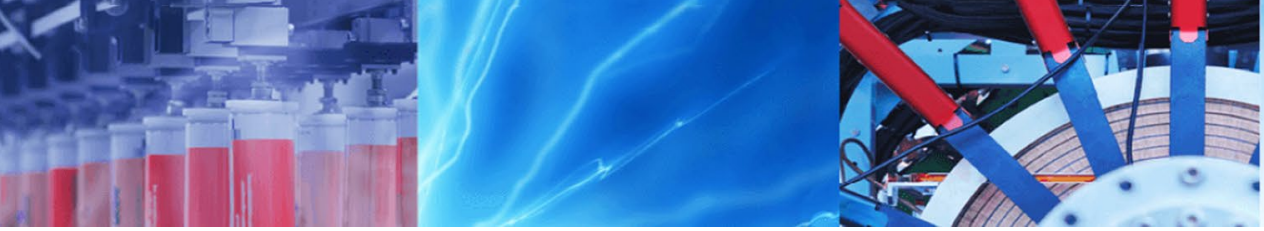

Research Article

\title{
Load-settlement mechanism of strip footings rested on saturated loose sand and improved by zeolite-cement pads
}

\author{
Sina Salamatpoor ${ }^{1} \cdot$ Siavash Salamatpoor $^{1}$
}

(c) Springer Nature Switzerland AG 2019

\begin{abstract}
This study aims to investigate the performance of cemented sand pads after being incorporated with zeolite. Therefore, mechanical properties of the prepared zeolite-cemented sand pads were measured by a series of unconfined compressive strength (UCS) tests. Also, several small $1 \mathrm{~g}$ model tests were conducted to evaluate the behavior of shallow foundations rested on the prepared pads. The results demonstrated a remarkable increase in the UCS of the 14 and 28 days cured pads containing $40 \mathrm{wt} \%$ zeolite. In addition, incorporating $40 \mathrm{wt} \%$ zeolite into the cemented sand pads improved both their strength improvement ratio (SIR) and settlement reduction ratio (SRR). In particular, the SIR and SRR of the pads containing $40 \mathrm{wt} \%$ zeolite improved up to $323 \%$ and $86 \%$ respectively compared to that of the pristine cemented sand pads. As such, adding zeolite to the cemented sand is one of the most promising candidate to overcome the shortcomings of sandy soils in backfills, roadbeds, embankments, and etc. It is notable that this method taking the advantages of easy fabrication, low cost, and absence of environmentally deleterious wastes.
\end{abstract}

Keywords Shallow foundation · Sand stabilized · Zeolite · UCS · Small-scale $1 \mathrm{~g}$ test

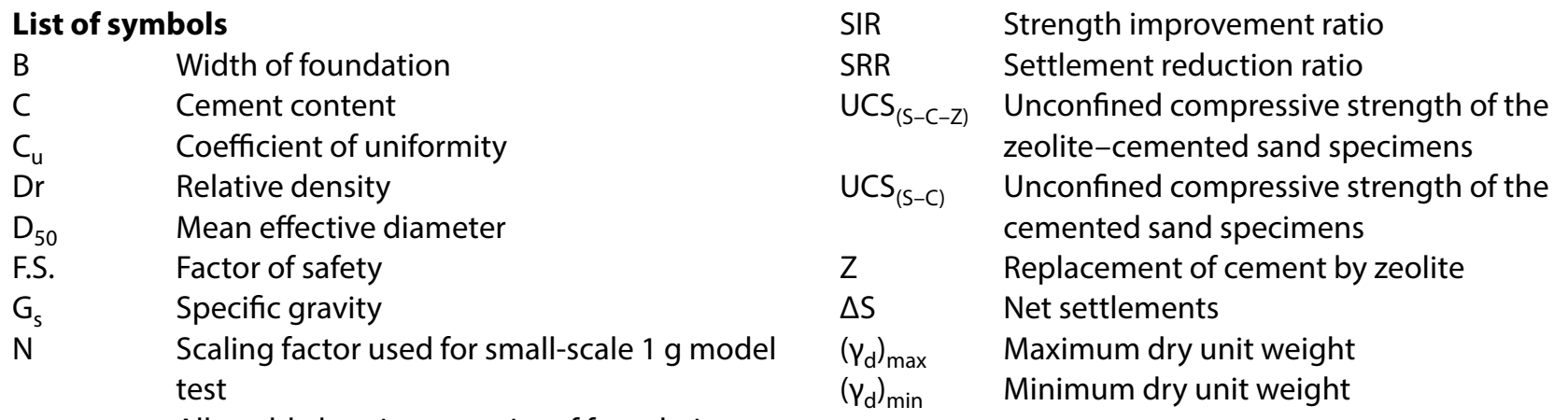

qall $\quad$ Allowable bearing capacity of foundation

$\mathrm{q}_{\mathrm{R}} \quad$ Strength ratio

$\mathrm{q}_{\mathrm{u}} \quad$ Unconfined compressive strength

$\mathrm{q}_{\mathrm{u}(\mathrm{s}-\mathrm{c}-\mathrm{z})} \quad$ Bearing capacity of foundation rested on stabilized sand (pad)

$\mathrm{q}_{\mathrm{u}(\mathrm{s}-\mathrm{c})} \quad$ Bearing capacity of foundation rested on unstabilized sand (without pad)

$\mathrm{R}^{2} \quad$ Coefficient of determination

$S$ Settlement of foundation

\section{Introduction}

Over the last century, several attempts have been made to stabilize loose sandy soils by incorporating them with cement. This is mainly because of the convenience, speed, simplicity, and cost effectiveness of this method. Inspired by the findings, adding certain content of cement to

Sina Salamatpoor, sina.salamatpoor@gmail.com; sina.salamatpoor@rouzbahan.ac.ir; Siavash Salamatpoor, ssalamatpoor@yahoo.com; ssalamatpoor@rouzbahan.ac.ir| 'Department of Civil Engineering, University College of Rouzbahan, Sari, Iran.

SN Applied Sciences (2019) 1:990 | https://doi.org/10.1007/s42452-019-1042-y 
the sandy soils benefits from improvement of the soil's strength, energy efficiency, sulfate resistance, shortening the hydration process (shorter setting time), and shrinking the soils' stiffness (reduction in the brittleness or plastic deformation). In total, existence of cement in sandy soils results in a significant improvement in their mechanical properties. Nevertheless, the downside of this approach is its negative environmental impacts.

In this regard, several attempts have been carried out to improve the mechanical behavior and compression strength of cemented sands using fillers, including fiber, glass, silica fume, fly ash, rice husk ash, nanoparticle, and metakaolin [1-7]. Recently, utilizing pozzolanic materials (such as zeolite) as a means of cement counterpart has become widespread to address environmental issues attributed to cement. In addition, replacing cement with pozzolanic materials can modify soil properties and save costs. Natural zeolite is made up of volcanic particles containing large quantities of reactive silicon dioxide $\left(\mathrm{SiO}_{2}\right)$ and aluminum oxide $\left(\mathrm{AL}_{2} \mathrm{O}_{3}\right)$. Calcium hydroxide $\left(\mathrm{Ca}(\mathrm{OH})_{2}\right)$ produced by hydration of Portland cement reacts with zeolite, leading to chemical improvement in the interfacial microstructure between the blended cement paste [8,9]. Generally, natural zeolite, which contains high pozzolanic activity, provides some benefits, including mechanical strength improvement, increasing durability of cement, and enhancing concrete properties [10,11].

Many recent papers focus on applicability of zeolite in terms of a permeable reactive barrier [12, 13], a landfill liner material mixed with bentonites [14], or its effect on the geotechnical properties of natural zeolite-soil blends $[15,16]$. Park et al. [15] added clinoptilolite to sand to fill the barriers, which were in contact with contaminated groundwater. The results revealed that filling the barriers with clinoptilolite and sand composites increased contaminants removal. Furthermore, it increased the sand's shearing resistance angle in the direct shear tests.

Whilst a considerable amount of literature has been carried out on improving load bearing capacity of foundations rested on loose sandy soils, there have been few experimental investigations into utilizing zeolite as a stabilizer of loose sandy soils. It is notable that loose sandy soils suffer from low shear strength both in liquefaction and limited liquefaction conditions. Hamed et al. [17] and Das [18] explored bearing capacity of a surface strip foundation rested on a loose sandy soil. The experiment was conducted by preparing a laboratory model test, where the foundation was supported by a granular trench equal with the foundation width. The results demonstrated a direct relationship between ultimate bearing capacity of the foundation and the granular trench depth. The authors reported that the bearing capacity of the footing remained constant when granular trench depth researched the maximum value. Lal et al. [19] investigated the behavior of a square shape footing placed on a loose sandy soil, which was reinforced with coir geotextile. The experiments were conducted for two distinct coir geotextile forms: geocell and planar. The results showed that $15 \%$ settlement to foundation width (with the same amount of material) ratio increased 7.9 and 5.83 order of magnitude the maximum bearing capacity of the geocell and planar coirs, respectively.

However, this study aims to utilize zeolite as a promising candidate to improve the performance of loose sandy soil. As a result, zeolite is incorporated into the cemented sand, which performs as a pad underneath a strip foundation. First, several unconfined compressive strength tests have been conducted to investigate mechanical behavior of the prepared zeolite-cement-sand pads. Then, the pad with optimum mixing ratio, concerning the highest strength, has been selected for placing underneath the foundation. In the second phase, a small-scale $1 \mathrm{~g}$ model has been made to investigate behavior of the strip foundation rested on the prepared pad. The objective of this study is to increase load bearing capacity of the strip foundation rested on the pad due to the chemical reactions between cement, sand and zeolite. Increasing the bearing capacity would ultimately reduce the foundation settlement.

\section{Experimental investigations}

\subsection{Materials}

The soil used in this study is sampled from Babolsar beach located in southern shores of the Caspian Sea in Iran. The grain size distribution curve of the soil is depicted in Fig. 1, which shows that the soil can be classified as poorly

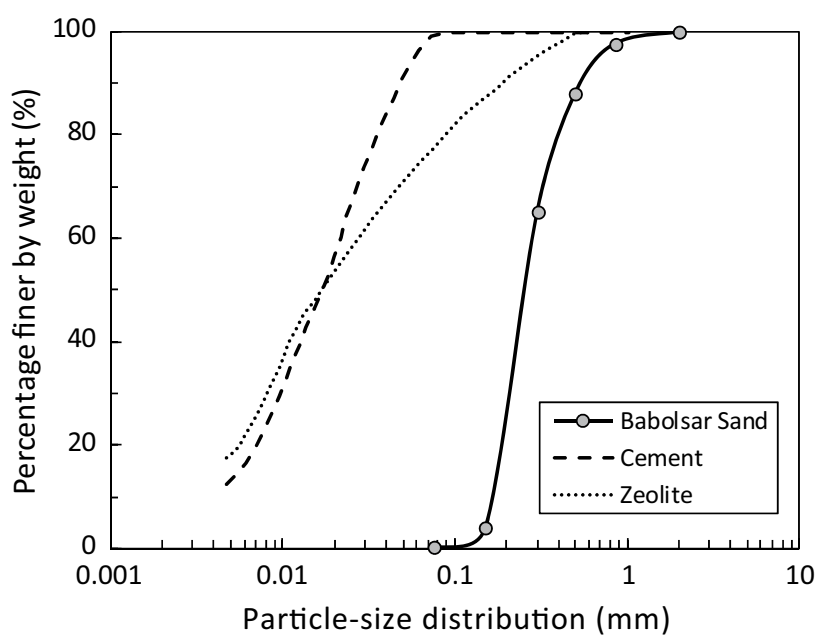

Fig. 1 Particle-size distribution curves of material used in this study 
graded sand (SP) based on Unified Soil Classification System (USCS) [20]. Table 1 shows the basic properties of this sand, its mineralogical composition, and its morphological characteristics [21, 22].

Due to high level of underground water in Babolsar, portland cement type II has been utilized, which is appropriate for structures exposed to soil/water containing sulfate ions [23]. The cement has been supplied from Mazandaran Cement Company, which provides cement for local construction industry.

Iran has abundant natural zeolites reservoirs. In a recently conducted study, the proven reserves of zeolite in Aftar mine, located $30 \mathrm{~km}$ far away from Semnan in Iran, is over 600 thousand tons [9]. It is notable that $85 \%$ of total zeolite extraction in the country is from this mine. Aftar zeolite, which is used in this study, can be classified as clinoptilolite type in the unified soil classification system $(G s=2.2)$ due to its low plasticity silt $(M L)$. Figure 1 presents grain-size distribution curves of the materials utilized in this study. Table 2 illustrates the chemical composition of the fabricated zeolite.

\section{Experimental procedures}

In this study, two series of experiments have been conducted. First, evaluating mechanical behavior of the prepared zeolite-cemented sand pads through unconfined compressive strength (UCS) tests to determine an optimum ratio of zeolite in the composite. In fact, the optimum proportion denotes the most efficient amount of zeolite in the sand, leading to the highest strength. Second, smallscale $1 \mathrm{~g}$ model tests to investigate the behavior of strip foundations rested on the pads, which have been prepared with respect to the optimum zeolite content. The details of small-scale $1 \mathrm{~g}$ model will be described later.

\subsection{Small-scale $1 \mathrm{~g}$ model test}

Concerning the study by Salamatpoor et al. [24], the experimental study involved three dominant equipment, including a frame, a transparent tank (as a rigid box), and
Table 2 Chemical composition of the natural zeolite of the clinoptilolite type

\begin{tabular}{ll}
\hline Details & Zeolite \\
\hline $\mathrm{SiO}_{2}$ & 67.79 \\
$\mathrm{Al}_{2} \mathrm{O}_{3}$ & 13.66 \\
$\mathrm{Fe}_{2} \mathrm{O}_{3}$ & 1.44 \\
$\mathrm{CaO}$ & 1.68 \\
$\mathrm{Na}_{2} \mathrm{O}$ & 2.04 \\
$\mathrm{~K}_{2} \mathrm{O}$ & 1.42 \\
$\mathrm{MgO}$ & 1.20 \\
$\mathrm{SO}$ & 0.50 \\
L.O.I (Loss on Ignition) & 10.23 \\
Specific gravity & 2.2 \\
Blaine (m²/kg) & 400 \\
\hline
\end{tabular}

measuring instruments. The frame is composed of IPE 18, which is screwed to a rigid foundation with eight M24 bolts. To avoid any possible displacement, angle bars and reinforcements are also welded to the frame. The dominant responsibility of the frame is to supply foundation loads by means of a jack. The transparent tank is made up of four $20 \mathrm{~mm}$ thick acrylic sheets with dimensions of $94 \mathrm{~cm} \times 40 \mathrm{~cm} \times 94 \mathrm{~cm}$. The tank is considered to be transparent to make it possible to observe the soil deformation underneath the foundations attributed to the wedge failure behavior.

To reinforce the test tank, a metal frame is integrated to all transparent sheets. The $15 \mathrm{~cm} \times 40 \mathrm{~cm}$ strip footing is composed of thick steel sheet, and some stiffeners are welded to the upper part of the sheet to secure its rigidity. A plain-strain condition is constantly maintained, since inside width of the box is equal to length of the prepared foundations. Before conducting the tests, for each test, some preparations are required to enhance the precision, such as calibrating the load cell and dialing the gauge. To achieve the required uniformity in the model, the sedimentation of soils in nature is mimicked for sand deposition. To start the tests, the tank is filled with de-aired water up to $70 \mathrm{~cm}$ height. Then, the sand, dried in an oven for $24 \mathrm{~h}$, is gradually poured by a sand shovel into the water from $2 \mathrm{~cm}$ above the water level. This procedure is continued until achieving the desired loose density. As the

Table 1 Basic properties, mineralogical composition and morphological characteristics of Babolsar sand

\begin{tabular}{|c|c|c|c|c|c|c|c|}
\hline Basic properties & & $\left(\gamma_{d}\right)_{\max }$ & & $\left(\gamma_{d}\right)_{\min }$ & $\mathrm{G}_{\mathrm{s}}$ & $\mathrm{D}_{50}(\mathrm{~mm})$ & $\mathrm{C}_{\mathrm{u}}$ \\
\hline & & 17 & & 15.1 & 2.78 & 0.24 & 1.8 \\
\hline & Quartz & & Feldspar & & Mica & Carbonate & Chlorite \\
\hline & $46 \%$ & & $27 \%$ & & $11 \%$ & $16 \%$ & 0 \\
\hline & \multicolumn{3}{|c|}{ Average shape factor } & & \multicolumn{2}{|c|}{ Average sphericity } & Average roundness \\
\hline & \multicolumn{3}{|c|}{0.89} & & \multicolumn{2}{|l|}{0.71} & 4.86 \\
\hline
\end{tabular}


width and the length of the testing tank are constant, the relative density is controlled by measuring both the height (or volume) and weight of each layers. It is considered to repeat the sand deposition with a relative density $\left(D_{r}\right)$ of $30 \pm 2 \%$ through a water sedimentation process.

The sand is deposited $70 \mathrm{~cm}$ in height, which provides enough thickness for the surface failure assigned to the foundation loading. This thickness has been verified by finite element modeling, where a $15 \mathrm{~cm}$ width foundation was load up to the maximum surcharge of $100 \mathrm{kPa}$. The results of the finite element modeling revealed that the optimal value for both depth of the sand and width of the test tank is $70 \mathrm{~cm}$. For the sake of brevity, the details of the finite element modeling have not been presented in this paper.

After filling the tank with sand and reaching the desired height, a zeolite-cement pad with specified dimensions as shown in Table 3, has been produced and cured similar with the UCS test. Afterwards, the pad has been placed directly in the middle of the box and coated with sand, whilst its top surface aligned with ground level. Finally, a strip footing has been placed exactly on top surface of the zeolite pad. Note that the length and width of the pad are equal with those of the strip footing.

Vertical loading of the footing and its corresponding settlement are measured by a load cell and three dial gauges, respectively. Figure 2 illustrates applied equipment for the small scale $1 \mathrm{~g}$ model test's. It is notable that it takes almost $8 \mathrm{~h}$ to fulfill the test preparations and the main test, whereas all mentioned steps should be repeated for each test individually. Importantly, the device and its utilities have been specifically designed and constructed for this study.

Table 3 Physical properties of the pad used in this study

\begin{tabular}{lllll}
\hline No. & Series & Thickness & C (\%) & $\begin{array}{l}\text { Z (\%) } \\
\text { (Opti- } \\
\text { mum) }\end{array}$ \\
\hline 1 & A & B/6 & 3 & 40 \\
2 & A & B/6 & 7 & 40 \\
3 & B & B/3 & 3 & 40 \\
4 & B & B/3 & 7 & 40 \\
5 & C & B/2 & 3 & 40 \\
6 & C & B/2 & 7 & 40 \\
7 & D & $2 B / 3$ & 3 & 40 \\
8 & D & $2 B / 3$ & 7 & 40 \\
9 & E & B & 7 & 40 \\
10 & E & B & 3 & 40 \\
\hline
\end{tabular}

B: Width of foundation in the present study $(15 \mathrm{~cm})$

Also, Length and width of pad in this study are equal to length and width foundation

SN Applied Sciences

APRINGER NATURE journa

\subsection{Model scaling}

Wood [25] suggested that physical modeling is one of the best approaches to overcome the limitations of analytical modeling. Precisely, in geotechnical engineering, the extracted data from physical modeling is applied for validation of analytical and numerical modeling.

Physical modeling is divided into two categories, including small-scale modeling and full-scale modeling. Full-scale physical modeling simulates the real site conditions such as ground conditions, pressures, and stress levels. However, due to the great challenges of modeling in the real conditions as well as the high costs, priority is given to the small-scale physical modeling with respect to the theory of similarity and scaling law.

Regarding ASTM D1194-72 [26] about plate load tests in granular soils, replacement of a prototype with $\mathrm{N}$ times smaller plate results in $\mathrm{N}$ times smaller ultimate bearing capacity compared to that of the real prototype. Therefore, herein, a small-scale model, which is 10 times smaller than the real prototype, has been built. For low levels of stress in small-scale modeling, the stress-strain behavior of the prototype has been attributed to the model [27]. Importantly, the specified scaling factors are presumed concerning the theory of scaling law defined by Wood [25].

\section{Results and discussions}

\subsection{Results of unconfined compression test}

\subsubsection{Investigation of stress-strain behavior}

This study aimed at investigating the effect of zeolite and cement content on the strength of zeolite-cementedsand pads. Thus, a series of laboratory tests have been conducted on Babolsar sand with either $3 \%$ or $7 \%$ cement to dry soil ratio. Then the cement has been replaced by zeolite in a weight percent of between 0 and $80 \%$ with $20 \%$ gaps. Finally, the composite samples have been cured within three different curing times, including 7, 14, and 28 days. The UCS test (conducted regarding ASTM D2166 [28]) has been selected to address the optimal zeolite concentration.

To investigate the behavior of stabilized soil in the UCS test, it is required to study the stress-strain curves. Figure 3 plots the results obtained from the unconfined compression tests for 28 days cured samples containing either $3 \%$ or $7 \%$ cement contents and were stabilized with the specified zeolite contents. As it can be seen, for both cement contents ( $3 \%$ and $7 \%$ ), the strain, which is correspondent to the peak stress, rises by increasing 


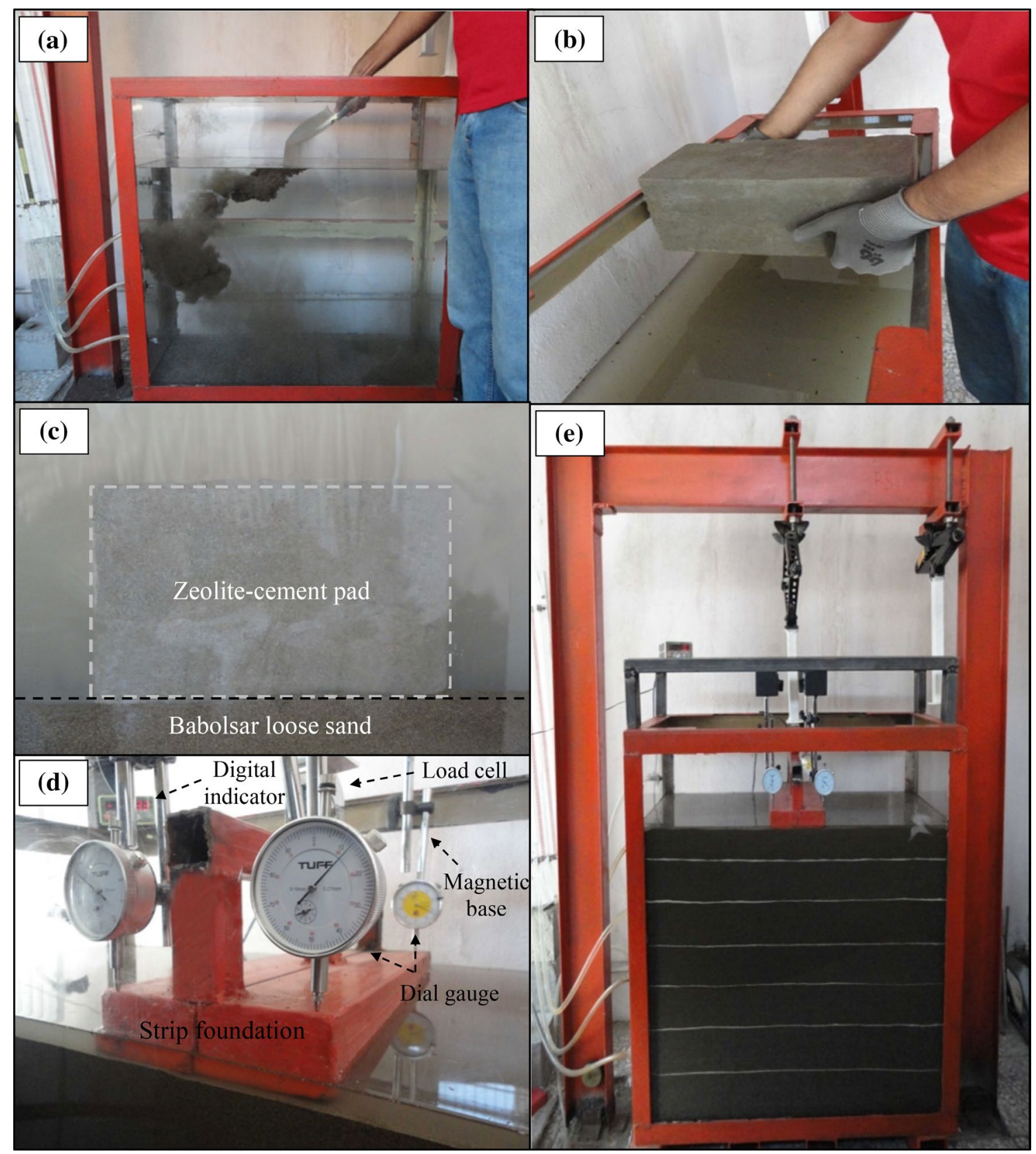

Fig. 2 a Pouring sand in the testing tank, b placing pad in the box $(\mathrm{H}=\mathrm{B})$, c front view of pad rested on the sand before sand deposition around it, $\mathbf{d}$ setting test facilities and instrumentation on the strip foundation, $\mathbf{e}$ view of small scale $1 \mathrm{~g}$ model test apparatus before the test

the zeolite content. Likewise, increasing cement to sand ratio (cement content) increases the highest strain, resulting in a decrease in the peak axial stress. This means that rising the zeolite content leads to failure in higher strains, which exhibits the plastic behavior of zeolite-cemented sand samples. Figure $3 \mathrm{~b}$ depicts that failure in $7 \%$ cement content is attributed to the rising of zeolite content, which decreases the brittle behavior of the sample (plastic deformation).

\subsubsection{Effects of zeolite on cemented sand strength}

Regarding the relationship between the zeolite content as an additive and the strength of the stabilized samples, Fig. $4 a$, $b$ show the maximum axial stress of samples with $3 \%$ and $7 \%$ cement content cured for 7,14 , or 28 days. As it can be seen, there is a tradeoff relationship between the compressive strength of the 7 days cured samples (either with $3 \%$ or $7 \%$ cement contents) and the zeolite concentration. To put it another way, increasing the zeolite 

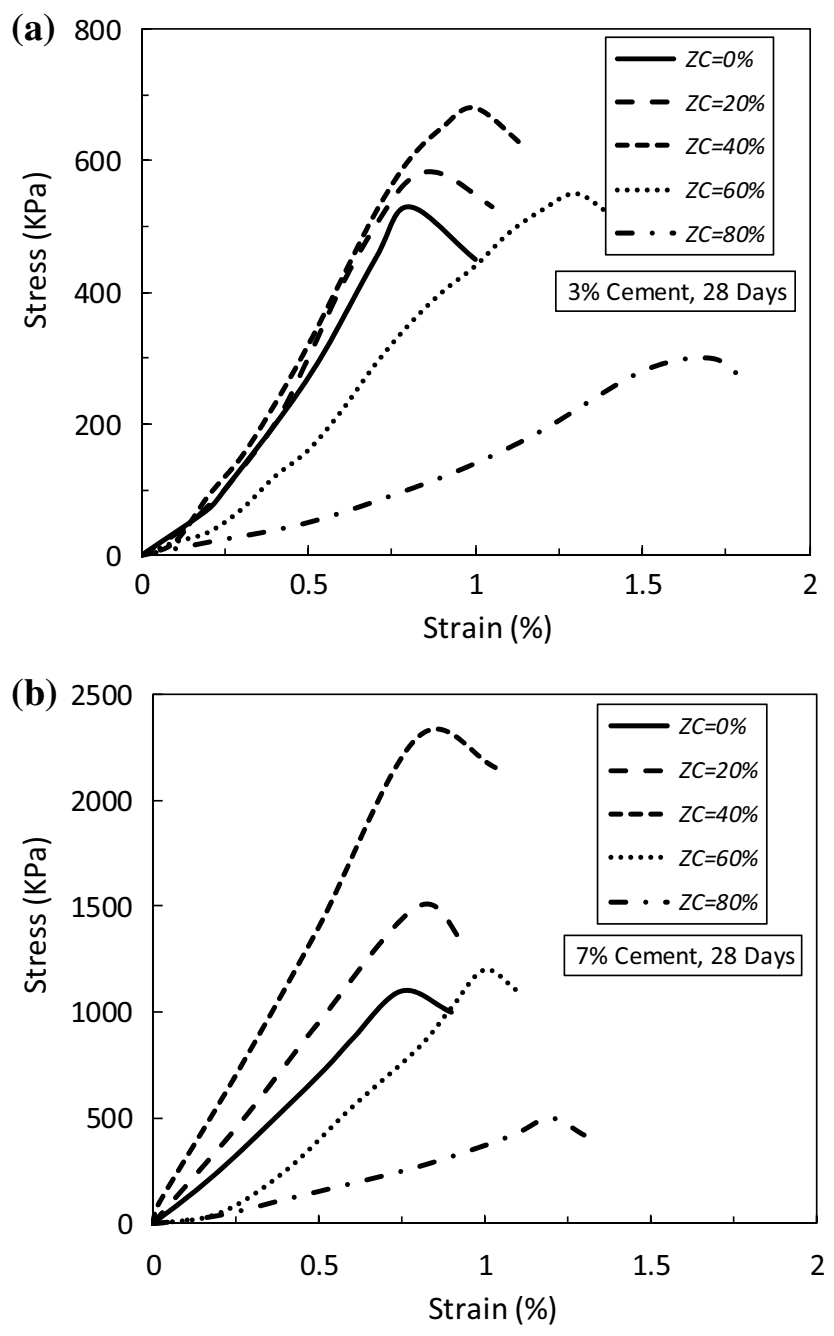

Fig. 3 Stress-strain curves of zeolite-cemented sand specimen with $3 \%$ cement and $7 \%$ cement after 28 days of curing

amount decreases the compressive strength of these samples. The dominant reason is that the pozzolanic reactions remain incomplete in such mixtures. However, increasing the weight percent of zeolite in 14 and 28 days cured samples initially enhances the compressive strength, but then proceeds a down ward trend. The highest compressive strength has been obtained by samples with an optimal zeolite content of $40 \mathrm{wt} \%$. In addition, the 28 days cured samples containing $7 \%$ cement content and $40 \mathrm{wt} \%$ zeolite concentration exhibit $238 \%$ higher strength compared with that of samples with $7 \%$ cement content with similar curing time and zeolite amount.

Moreover, adding $60 \mathrm{wt} \%$ zeolite increases the strength rate up to $9 \%$ for the 28 days cured samples containing $7 \%$ cement content. However, this increase is only $2 \%$ for the samples with 14 days curing time and $3 \%$ cement content. Therefore, it could be interpreted that the compressive strength of the cemented sand samples
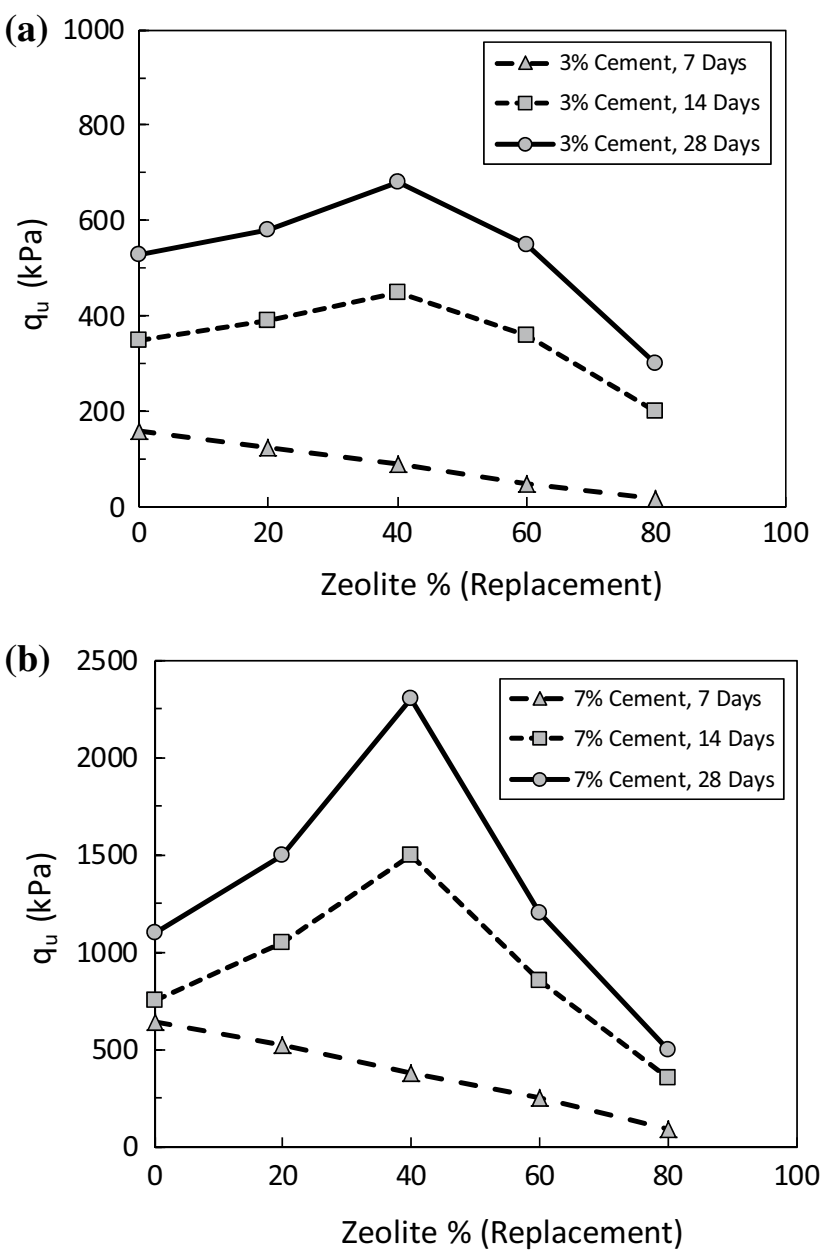

Fig. 4 Effects of zeolite on $\mathrm{q}_{\mathrm{u}}$ of cemented sand specimen a $3 \%$ cement at 7, 14, 28 days of curing, $\mathbf{b} 7 \%$ cement at 7, 14, 28 days of curing

increases by increasing the zeolite content up to $60 \mathrm{wt} \%$, but further increase in the zeolite content results in lower strength compared to that of the pristine cemented sand specimens.

\subsubsection{Strength increase characteristic}

As mentioned earlier, previous studies proved that the mechanical strength of cement samples can be improve by using a specific amount of additives [7]. Herein, the impact of adding zeolite on the behavior of cemented sand samples is qualified by strength ratio $\left(\mathrm{q}_{\mathrm{R}}\right)$ as an index parameter.

The relationship between the UCS of the cement samples stabilized by zeolite and the $q_{R}$ value is depicted in Eq. (1).

$\mathrm{q}_{\mathrm{R}}=\frac{\mathrm{UCS}_{(\mathrm{S}-\mathrm{C}-\mathrm{Z})}}{\mathrm{UCS}_{(\mathrm{S}-\mathrm{C})}}$

\section{SN Applied Sciences}


where S-C-Z refers to the stabilized zeolite-cemented sand samples and $\mathrm{S}-\mathrm{C}$ denotes the pristine cemented sand samples. Figure 5 shows the strength ratios of the stabilized samples with cement contents of $3 \%$ and $7 \%$ and curing time of 14 and 28 days. As it can be seen, for the samples with 40 wt $\%$ zeolite and 28 days curing time, the $q_{R}$ value increases 2.09 and 1.28 order of magnitude respectively in the samples with $7 \%$ and $3 \%$ cement contents. Whereas, for the 14 days cured samples, the $q_{R}$ increases respectively 2 and 1.28 order of magnitude. Importantly, or the 28 days cured samples with 40 wt $\%$ zeolite content, rising the cement content from $3 \%$ to $7 \%$ increases the $q_{R}$ value up to $63 \%$ (Fig. 5a), which is $7 \%$ higher than that of the 14 days cured specimens (Fig. 5b). The primary reason is the greater reaction of zeolite with calcium hydroxide $\left(\left(\mathrm{Ca}(\mathrm{OH})_{2}\right)\right.$ in the $7 \%$ cemented samples, resulting in lower porosity and ultimately greater strength. However, increasing the zeolite content more than $40 \mathrm{wt} \%$ deteriorates the strength ratio attributed to the limited pozzolanic reactions. To illustrate, more than $40 \mathrm{wt} \%$ zeolite content fills the capillary gaps between zeolite and its sedimentation with gel, which precludes creating of the calcium silicate hydrates $(\mathrm{C}-\mathrm{S}-\mathrm{H})$ gel as a means of cohesion and strength in the cement paste. Hence, in this study, $40 \mathrm{wt} \%$ zeolite content is determined as an optimal amount of replacing cement with zeolite. However, for 7 days cured samples, all specified zeolite contents have an inverse relationship with the strength ratio, as shown in (Fig. 5C).

\subsection{Small-scale $1 \mathrm{~g}$ model test}

\subsubsection{Effect of zeolite-cement pad on bearing capacity foundation}

In the second part of this study, a series of small-scale $1 \mathrm{~g}$ model tests were conducted to evaluate the behavior of strip foundations rested on the saturated sands (resembles the condition of Babolsar sands) stabilized by a pad composed of the optimal zeolite cemented sand mixture. Regarding the results obtained from the compressive
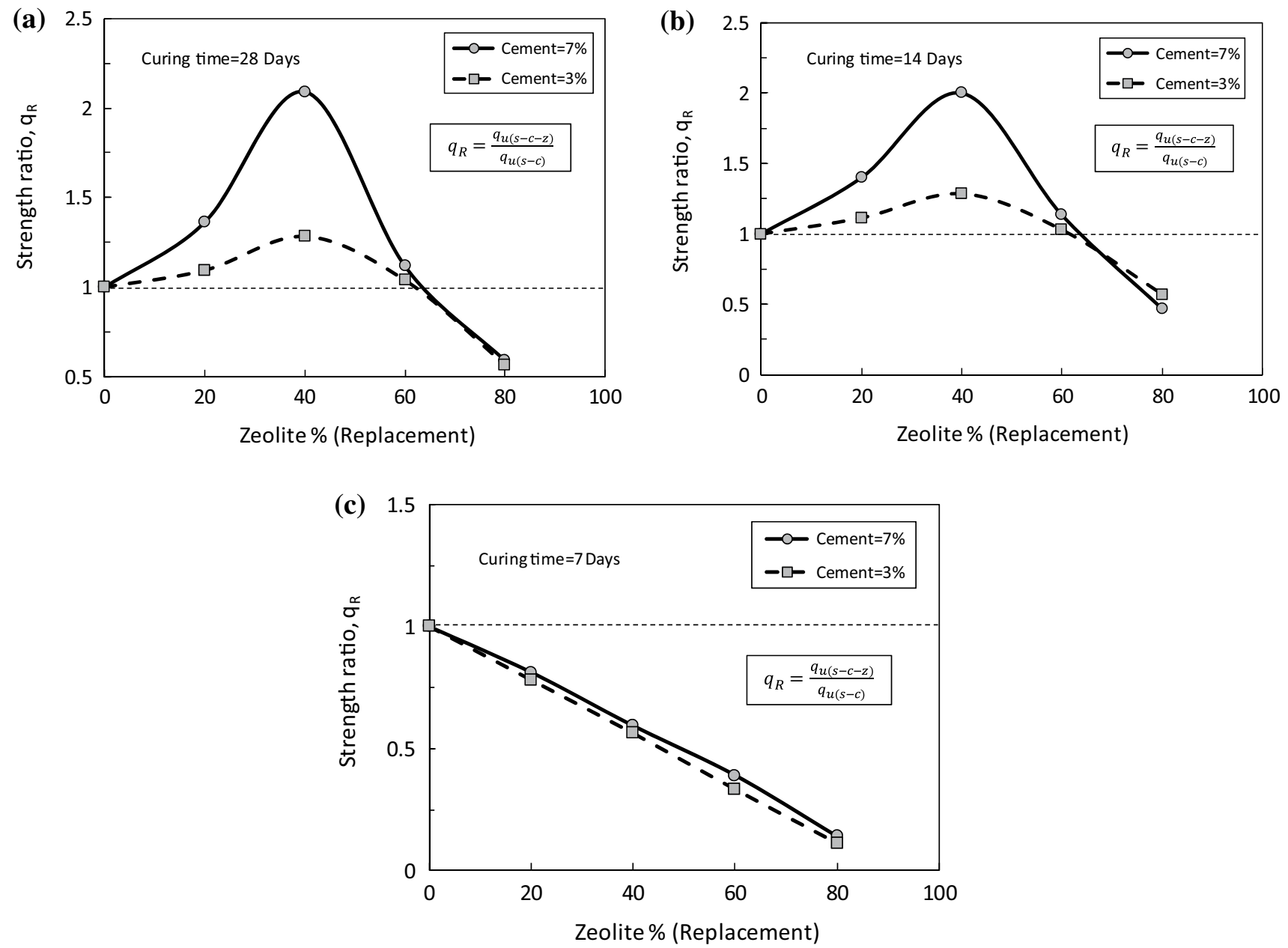

Fig. 5 Strength ratio versus zeolite content for a 28 days, b 14 days, $\mathbf{c} 7$ days curing times 
strength tests, $40 \mathrm{wt} \%$ zeolite has been determined as an optimal weight percent of zeolite content in the pads. Table 3 shows the properties of the 28 days cured pads constructed for the physical model tests.

Figure 6 a plots the stress-settlement curve of the strip foundation rested on the zeolite cemented pad for tests A, C and E. The load-settlement curves achieved by the experimental studies exhibits that the ultimate bearing capacity of a shallow foundation rested on sandy soil could be determined by various approaches. De Beer [29] suggests that the corresponding load to the intersecting tangents of the two linear portions of the load-settlement curve can be defined as the ultimate bearing capacity.

(a)

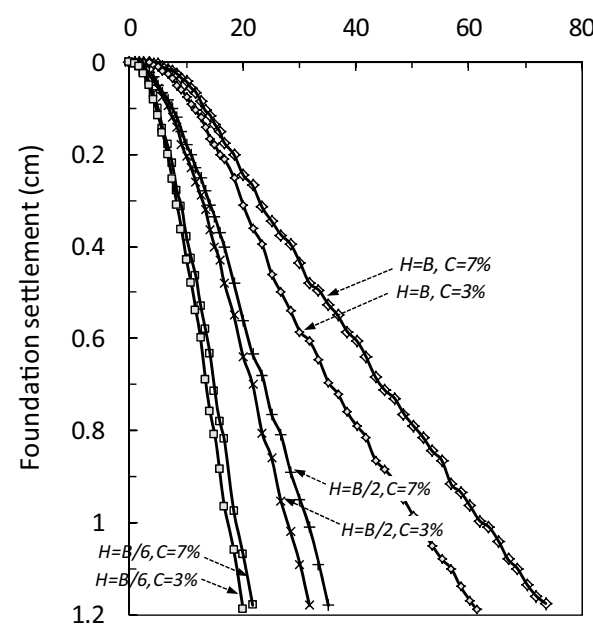

(b)

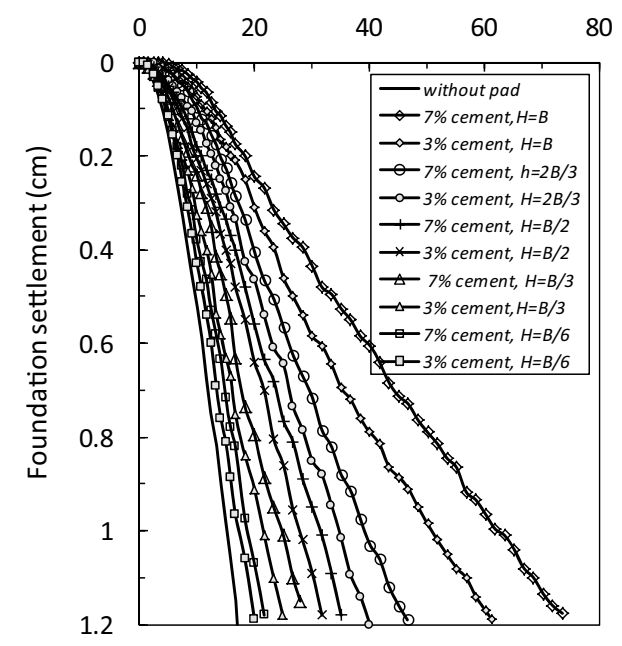

Fig. 6 Curves of bearing pressure against foundation settlement in cases of a A, C and E series, $\mathbf{b}$ different thickness of pad with $3 \%$ and $7 \%$ cement contents in small-scale $1 \mathrm{~g}$ model test (note: the optimum value of $40 \%$ cement replacement by zeolite and 28 days curing time were considered for all samples)
However, Vesic [30] and Das [31] demonstrate the ultimate bearing capacity as a load corresponding to $~ 5 \%$ to $15 \%$ $(\mathrm{S} / \mathrm{B}=0.05-0.15)$ and $\sim 15 \%$ to $25 \%(\mathrm{~S} / \mathrm{B}=0.15 \sim 0.25)$ of settlement, where $B$ is equal to the foundation width. In this study, the ultimate bearing capacity of each footing has been determined through considering with respect to the Das [31] method with a settlement correspondent to $20 \%$ of the foundation width $(S / B=0.2)$.

The ultimate bearing capacity of a foundation without a pad underneath, rested on the saturated sand, is equal to $0.15 \mathrm{~kg} / \mathrm{cm}^{2}$. However, placing a pad with a thickness onesixth of the foundation width $(B / 6)$ underneath the strip foundations increases the ultimate bearing capacity of the samples with $3 \%$ cement content (A1) and $7 \%$ cement content (A2) up to $16.7 \mathrm{kPa}$ and $18.4 \mathrm{kPa}$, respectively. In particular, the ultimate bearing capacity of $A 2$ enhanced $9 \%$ more than that of $A 1$.

Samples C containing 3\% (C5) and 7\% (C6) cement content display $67 \%$ and $76 \%$ greater strength improvement compared with their corresponding A series samples, respectively. Increasing the pad width up to 6 order of magnitude leads to $310 \%$ greater strength of E9 compared with $A 1$, and $340 \%$ higher strength of $E 10$ relative to A2. The strength of E9 and E10 are respectively $354 \%$ and $423 \%$ higher than strip foundations without a pad. Consequently, there is a direct relationship between increasing the pad thickness and the bearing capacity, while there is an inverse relationship between increasing the pad thickness and the foundation's settlement.

Figure $6 \mathrm{~b}$ plots the stress-settlement curves of all specified conditions in Table 3. Accordingly, the relationship between the stress and settlement is nonlinear for loading in low values. This linear trend could be attributed to the punching shear failure of the foundation. However, the relationship between the stress and settlement gets a linear trend with a high value loading. Comparing E9 and E10, with similar pad thickness to foundation ratios but different cement contents, the former showed $23 \%$ greater bearing capacity than the latter. In addition, for samples A to $D$, this increase is $9 \%, 12 \%, 14 \%$, and $19 \%$ respectively, meaning that the effect of cement content is greater on the thicker pads.

\subsubsection{Strength improvement and settlement reduction ratios}

To precisely investigate the influence of fabricating zeolite cemented pad underneath the strip foundations, two methods of strength improvement ratio (SIR) and settlement reduction ratio (SRR) have been utilized as follow:

$\mathrm{SIR}=\frac{\mathrm{q}_{\mathrm{u}(\text { stabilized) }}-\mathrm{q}_{\mathrm{u}(\text { unstabilized })}}{\mathrm{q}_{\mathrm{u} \text { (unstabilized) }}}$ 
$\mathrm{SRR}=\frac{\mathrm{S}_{\text {(unstabilized) }}-\mathrm{S}_{\text {(stabilized) }}}{\mathrm{S}_{(\text {unstabilized) }}}$

where $\mathrm{q}_{\mathrm{u}(\text { (stabilized) and }} \mathrm{q}_{\mathrm{u} \text { (unstabilized) }}$ are ultimate bearing capacity of the foundation with or without a pad underneath, respectively. Also $S_{(\text {(stabilized) }}$ and $S_{\text {(unstabilized) }}$ refers to the foundation settlement with and without the pad, respectively. Here, the SRR is defined as the ratio of a foundation's settlement stabilized with a pad to that of without a pad at a specified footing pressure $(q=15 \mathrm{kPa})$.

Figures $7 \mathrm{a}$, b plot the strength improvement ratio and the settlement reduction coefficient as a function of $H / B$, where $H / B$ is the ratio of the pad thickness to the foundation width. As it can be seen, increasing the $\mathrm{H} / \mathrm{B}$ ratio results in rising of the SIR value. Regarding the foundations without a pad underneath, the SIR value of samples without pad underneath the foundation is equal to 0 . However, the SIR value for the $\mathrm{H} / \mathrm{B}$ ratio of $1 / 6$, $1 / 3,1 / 2,2 / 3$, and 1 is equal to $0.22,0.67,1.12,1.67$, and

(a)

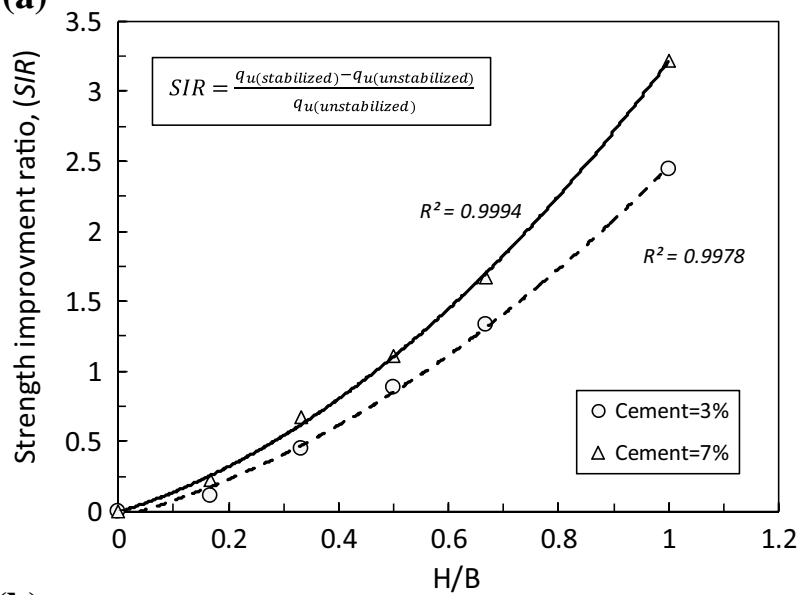

(b)

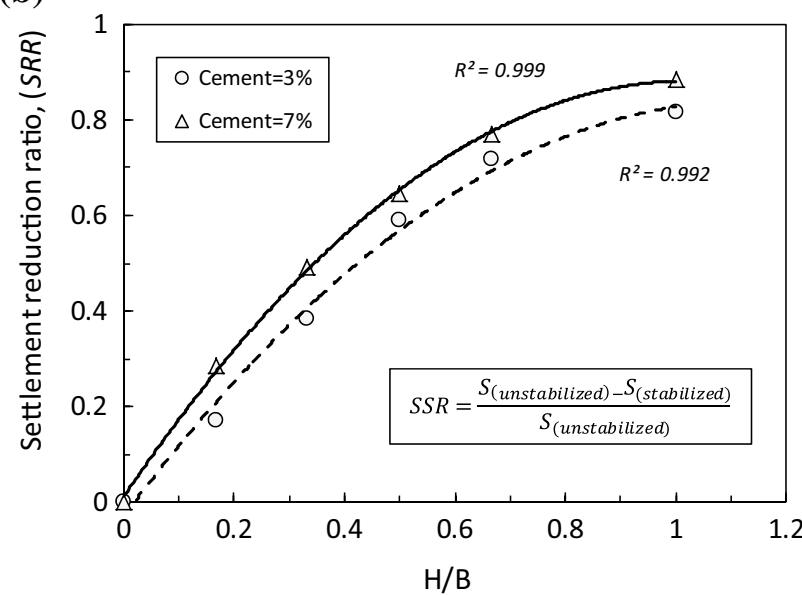

Fig. 7 Variations of a strength improvement ratio (SIR) and $\mathbf{b}$ settlement reduction ratio (SRR) versus $\mathrm{H} / \mathrm{B}$ ratio for all tests
3.23 , respectively (with $7 \%$ cement content). Moreover, increasing the cement content from $3 \%$ to $7 \%$ causes an enhancement in the SIR value, which is greater at higher $\mathrm{H} / \mathrm{B}$ ratios (see Fig. 7a).

As shown in Fig. 7b, placing a pad with a thickness of $B / 6$ ( $A 2$ sample) underneath the foundation leads to reduction in the settlement rate up to $26 \%$ compared to that of without a pad. For the $\mathrm{H}$ to $\mathrm{B}$ ratios of $1 / 3$ (B2), $1 / 2$ (C2), 2/3 (D2), and 1 (E2) with the cement content of $7 \%$, the SRR rate decreases up to $65 \%, 76 \%$, and $86 \%$, respectively. Therefore, increasing the $\mathrm{H} / \mathrm{B}$ ratio leads to reduction in SRR value. Also, increasing the cement content from $3 \%$ to $7 \%$ changes the SRR value of all specified $\mathrm{H} / \mathrm{B}$ ratios up to $6 \%$. Accordingly, in spite of the greater effect of cement content on SIR in higher $H / B$ ratios, it has no influence on SRR by increasing the $H / B$ ratios. For all curves, the coefficients of determination values $\left(R^{2}\right)$ are greater than 0.95 , which indicates the alignment between the regression lines and the data.

Figure 8 illustrates SRR rates as a function of SIR for all listed tests in Table 3. As it is depicted, using a pad with a thickness up to $2 / 3$ of the foundation width increases both the SRR and SIR rates linearly (a sharp slope). These risings will be continued by increasing the pad thickness up to the foundation width $(H / B=1)$. However, SIR rate shows a great jump at $H / B$ ratio of 1 owing to the increase in the strength rate, while the SRR, which resembles the settlement reduction, shows a gentle rising trend. Therefore, it can be said that applying a pad with a thickness lower than the foundation width increases both the SIR and SRR values remarkably. However, increasing its thickness up to the foundation width only improves the SIR value, but not the SRR.

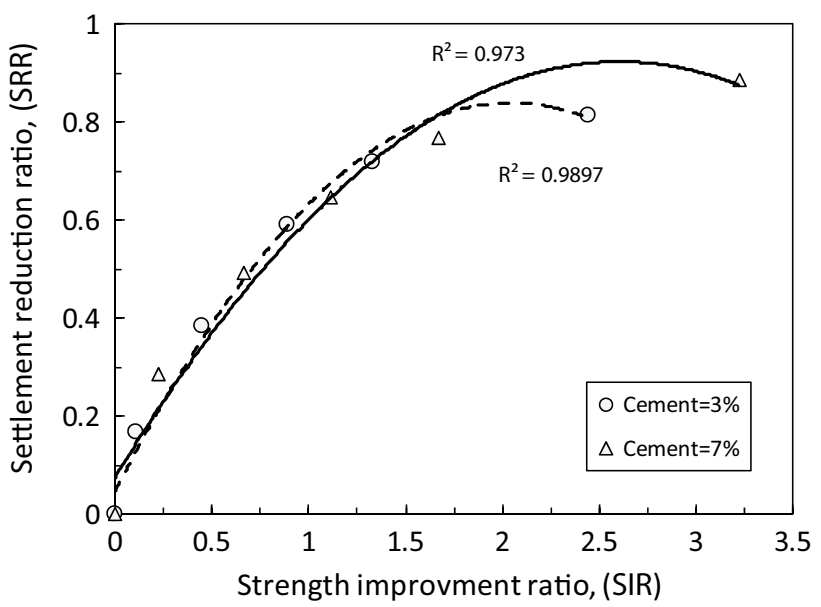

Fig. 8 Variations strength improvement ratio (SIR) versus settlement reduction ratio (SRR) for all tests 


\subsubsection{Allowable bearing capacity zeolite-cemented pad}

Safety factor is an essential parameter in building design, which shows the ratio between the strength of the material and the maximum stress in the part. Safety factors are determined in building codes regarding the regular stress in a specific position. However, engineers mostly overengineer all parts by considering the superior safety factors in order to provide safety against probable emergency situations, unpredicted forces and poor quality construction. In this case, this is not desirable either, because of wasting material resources and increasing the cost.

The allowable bearing capacity, which is the maximum bearing stress that can be applied to the soil from the foundation, is normally driven from ultimate bearing capacity using a factor of safety. It is notable that the ultimate bearing capacity is the maximum pressure that can be supported by the foundation, but initiates the failure. Therefore, knowing the optimal safety factor makes balance between a safe loading without the risk of foundation settlement and saving the project costs. Equation 4 displays the relationship between the allowable bearing capacity, the ultimate bearing capacity, and the safety factor.

$\mathrm{q}_{\mathrm{all}}=\frac{\mathrm{q}_{\mathrm{ult}}}{\mathrm{F} . \mathrm{S} \text {. }}$

where $\mathrm{q}_{\mathrm{ult}}$ and $\mathrm{q}_{\mathrm{all}}$ are respectively the ultimate and allowable bearing capacity, and F.S. is the safety factor. The selected safety factors in this study are 2 and 3, which were calculated by building Codes with respect to overturning and sliding of shallow foundation in shear failure mood. Figure 9a illustrates the allowable bearing capacity against F.S. for all tests determined in Table 3. As it can be seen, for both cement contents the greatest bearing capacity difference is occurred between samples $D$ and E. With a safety factor equal to 2 , the strength increases up to $59 \%$ and $48 \%$ for the $7 \%$ and $3 \%$ cement content samples, respectively. In addition, increasing the safety factor from 2 to 3 results in a minor difference between the allowable bearing capacity of the foundation placed on a pad with $B / 6$ width (samples $A$ ) and that of without a pad. This result proves that excessing the safety factors over the required margin of safety does not ensure a safer foundation. Figure $9 \mathrm{~b}$ exhibits the correlation between the allowable bearing capacity and the net settlement $(\Delta S)$ normalized by the foundation width for $7 \%$ cement content specimens with different employed safety factors. For a given safety factor, the allowable bearing capacity raised by increasing the net settlement ratio. Increasing the pad thickness $(\Delta S / B>0.03)$ accelerates rising of the allowable bearing capacity and decreases the settlement difference especially with the pads possessing $\Delta S / B<0.0$ thickness.
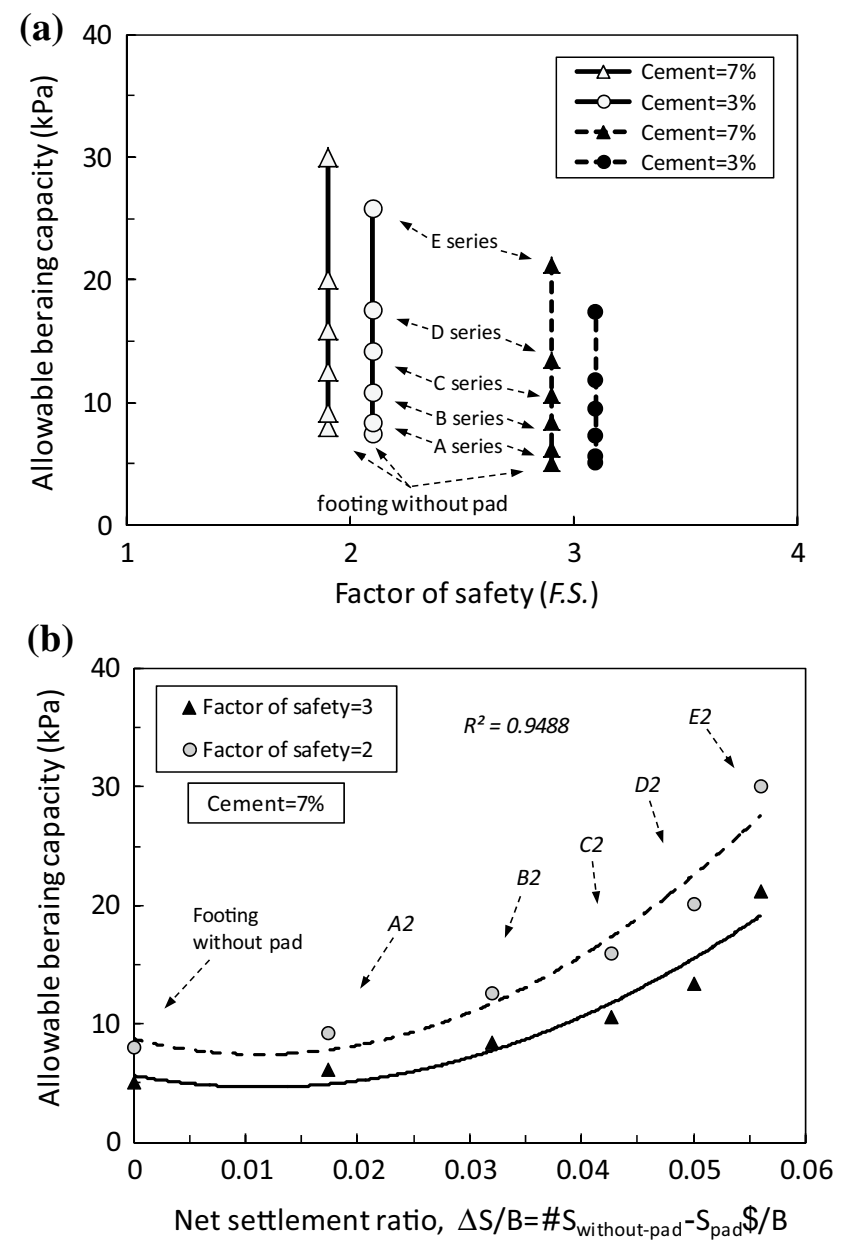

Fig. 9 Variations of allowable bearing capacity versus, a factor of safety for all tests, b normalized foundation settlement (note $\Delta \mathrm{S}$ : difference of foundation settlement in pad and the without pad value under consideration)

Changing the pads thickness and cement contents, selecting a proper safety factor significantly effects on the shallow foundations settlement, as shown in Figs. 9a, b. Therefore, applying an appropriate safety factor is a striking factor for controlling the buildings settlements. Although optimum bearing capacity can be achieved by pads with greater thickness, but the ones with lower thickness are more desirable regarding the settlement. It is notable that utilizing a pad with thickness more than $\mathrm{B} / 3$ faces construction restrictions in a real-life practice. To make balance between an optimal bearing capacity and settlement, a pad with thickness less than $B / 3$ shows superior results by increasing the bearing capacity in the range between $23 \%$ and $67 \%$ and improving the settlement up to $19-49 \%$. Furthermore, this thickness confronts no limitations in practice. Consequently, $B / 3$ is the suggested thickness for the pads to vindicate the foundations rested on low shear strength soils. 


\section{Conclusions}

Based on the experimental results of the present study, key findings are:

(1) Replacing cement with zeolite up to $40 \mathrm{wt} \%$ increases the compressive strength up to $128 \%$ and $209 \%$ for samples cured over 14 and 28 days, respectively. The reason is primary because of the pozzolanic activity of zeolite and reduction in hydration reaction by excessing the curing time. As a result, herein, the optimal zeolite content is suggested to be $40 \mathrm{wt} \%$.

(2) Replacing $40 \mathrm{wt} \%$ of cement with zeolite, the $q_{R}$ of samples (cured for 28 days) with $7 \%$ and $3 \%$ cement content increases 2.09 and 1.28 orders of factors, respectively, However, above $40 \mathrm{wt} \%$ replacement leads to reduction in the $q_{R}$ of the cemented sand samples.

(3) Adding zeolite to the cemented sand samples increases the axial strain at the peak strength compared with that of pristine cemented sand samples. The dominant reason is that fabricating zeolite changes the samples operation from brittle to plastic (postponing the failure rate). The deformability index of 28 days cured samples containing $3 \%$ cement content shows that adding $20 \mathrm{wt} \%, 40 \mathrm{wt} \%, 60 \mathrm{wt} \%$ and $80 \mathrm{wt} \%$ zeolite content enhances the plastic behavior up to $1.12,1.37,1.62$, and 2.12 order of magnitude compared with that of pristine cemented sand samples.

(4) Stabilizing strip footings by fabricating a pad with a thickness $1 / 6$ of the foundation width increases the bearing capacity up to $11 \%$ and $23 \%$ when the pads contain either $3 \%$ or $7 \%$ cement content, respectively. Further increase in the pad thickness (up to 2 times) improves the bearing capacity up to $44 \%$ and $67 \%$. As a result, utilizing a pad underneath the strip foundations, which are rested on saturated loose sand, increases the bearing capacity and ultimately reduces the settlement.

(5) Rising the H/B ratio results in increasing of the SIR and reduction in the SRR. It is noteworthy that increasing the cement content causes an increase in the SIR rate up to $9 \%$ and $23 \%$ when $\mathrm{H}$ to $\mathrm{B}$ ratio is $1 / 6$ and 1 , respectively. However, the increase in the SRR due to increasing the cement content remains constant at $6 \%$.

(6) Last but not least, utilizing a zeolite-cemented pad with thickness greater than $2 B / 3$ accelerates the rising of SIR rate compared with that of thinner pads, while the SRR rate remains almost constant.

\section{Compliance with ethical standards}

Conflict of interest All the authors declare that they have no conflict of interest.

\section{References}

1. Chauhan MS, Mittal S, Mohanty B (2008) Performance evaluation of silty sand subgrade reinforced with fly ash and fibre. Geotext Geomembr 26(5):429-435. https://doi.org/10.1016/j. geotexmem.2008.02.001

2. Consoli NC, Foppa D (2014) Porosity/cement ratio controlling initial bulk modulus and incremental yield stress of an artificially cemented soil cured under stress. Geotech Lett 4(1):22-26. https ://doi.org/10.1680/geolett.13.00081

3. Ayeldeen M, Hara Y, Kitazume M, Negm A (2016) Unconfined compressive strength of compacted disturbed cement-stabilized soft clay. Int J Geosynth Ground Eng 2:28. https://doi. org/10.1007/s40891-016-0064-4

4. Boddy A, Hooton R, Gruber K (2001) Long-term testing of the chloride-penetration resistance of concrete containing highreactivity metakaolin. Cem Concr Res 31(5):759-765. https://doi. org/10.1016/S0008-8846(01)00492-6

5. Ismail MA (2005) Performance of cement-stabilized retaining walls. Can Geotech J 42(3):876-891. https://doi.org/10.1139/ t05-021

6. Chindaprasirt P, Rukzon S, Sirivivatnanon V (2008) Resistance to chloride penetration of blended Portland cement mortar containing palm oil fuel ash, rice husk ash and fly ash. Constr Build Mater 22(5):932-938. https://doi.org/10.1016/j.conbuildma t.2006.12.001

7. Salamatpoor S, Salamatpoor S (2017) Evaluation of adding crushed glass to different combinations of cement-stabilized sand. Int J of Geo-Eng 8(8):1-12. https://doi.org/10.1186/s4070 3-017-0044-0

8. Caputo D, Liguori B, Colella C (2008) Some advances in understanding the pozzolanic activity of zeolites: the effect of zeolite structure. Cem Concr Compos 30(5):455-462. https://doi. org/10.1016/j.cemconcomp.2007.08.004

9. Salamatpoor S, Jafarian Y, Hajiannia A (2018) Physical and mechanical properties of sand stabilized by cement and natural zeolite. Eur Phys J Plus 133:205. https://doi.org/10.1140/epjp/ i2018-12016-0

10. Bilim C (2011) Properties of cement mortars containing clinoptilolite as a supplementary cementitious material. Constr Build Mater 25(8):3175-3180. https://doi.org/10.1016/j.conbuildma t.2011.02.006

11. Ramezanianpour AA, Kazemian A, Sarvari M, Ahmadi B (2013) Use of natural zeolite to produce self-consolidating concrete with low portland cement content and high durability. J Mater Civ Eng 25(5):589-596. https://doi.org/10.1061/(ASCE)MT.19435533.0000621

12. Woinarski AZ, Stevens GW, Snape I (2006) A natural zeolite permeable reactive barrier to treat heavy-metal contaminated waters in Antarctica: kinetic and fixed bed studies. Process Saf Environ Prot 84(2):109-116. https://doi.org/10.1205/psep.04296

13. Thiruvenkatachari R, Vigneswaran S, Naidu R (2008) Permeable reactive barrier for groundwater contamination. J Ind Eng Chem 14(2):145-156. https://doi.org/10.1016/j.jiec.2007.10.001

14. Kaya A, Durukan S (2004) Utilization of bentonite-embedded zeolite as clay liner. Appl Clay Sci 25(1-2):83-91. https://doi. org/10.1016/j.clay.2003.07.002 
15. Park JB, Lee SH, Lee JW, Lee CY (2002) Lab scale experiments for permeable reactive barriers against contaminated groundwater with ammonium and heavy metals using clinoptilolite (01-29B). J Hazard Mater 95(1-2):65-79. https://doi.org/10.1016/S0304 -3894(02)00007-9

16. Georgiannou VN, Lefas D, Konstadinou M, Perraki M (2017) Geotechnical properties of a natural zeolite. Proc Inst Civ EngGeotech Eng 170(5):395-406. https://doi.org/10.1680/jgeen .16 .00157

17. Hamed JT, Das BM, Echelberger WF (1986) Bearing capacity of a strip foundation on granular trench in soft clay. Civ Eng Pract Des Eng 5(5):359-376

18. Das BM (1988) Bearing capacity of shallow foundation on a granular trench in ground. In: Proceedings of the 5th AustraliaNew Zealand conference on geomechanics, Barton, Australia, pp 278-282

19. Lal D, Sankar N, Chandrakaran S (2017) Effect of reinforcement form on the behaviour of coir geotextile reinforced sand beds. Soils Found 57(2):227-236. https://doi.org/10.1016/j.sandf .2016.12.001

20. ASTM D2487 (2000) Standard classification of soils for engineering purposes. ASTM International, West Conshohocken

21. Jafarian Y, Ghorbani A, Salamatpoor S, Salamatpoor S (2013) Monotonic triaxial experiments to evaluate steady-state and liquefaction susceptibility of Babolsar sand. J Zhejiang Univ Sci A 14(10):739-750. https://doi.org/10.1631/jzus.A1300032

22. Salamatpoor S, Salamatpoor S (2014) Evaluation of Babolsar sand behaviour by using static triaxial tests and comparison with case history. Open J Civ Eng 4(3):181-197. https://doi. org/10.4236/ojce.2014.43016
23. ASTM C150/C150 M-17 (2017) Standard specification for Portland cement. ASTM International, West Conshohocken

24. Salamatpoor S, Jafarian Y, Hajiannia A (2018) Improving shallow foundations resting on saturated loose sand by a zeolitecement mixture: a laboratory study. Sci Iran A 25(4):2063-2076. https://doi.org/10.24200/sci.2018.50153.1567

25. Wood DM (2004) Geotechnical modeling, 1st edn. Spon press, London

26. ASTM D1 194-72 (1987) Standard test method for bearing capacity of soil for static load and spread footings. ASTM International, West Conshohocken

27. Jafarian Y, Haddad A, Mehrzad B (2016) Load-settlement mechanism of shallow foundations rested on saturated sand with upward seepage. Int J Geomech 17(3):1-14. https://doi. org/10.1061/(ASCE)GM.1943-5622.0000777

28. ASTM D2166 (2006) Standard test method for unconfined compressive strength of cohesive soil. ASTM International, West Conshohocken

29. De Beer EE (1970) Experimental determination of the shape factors and the bearing capacity factors of sand. Geotech 20(4):387-411

30. Vesic AS (1973) Analysis of ultimate loads of shallow foundations. J Soil Mech Found Div 99(1):45-73

31. Das BM (2009) Shallow foundations: bearing capacity and settlement, 2nd edn. CRC Press, Boca Raton

Publisher's Note Springer Nature remains neutral with regard to jurisdictional claims in published maps and institutional affiliations. 